\title{
Studies in Porphyria
}

\author{
FUNCTIONAL EVIDENCE FOR A PARTIAL DEFICIENCY OF \\ FERROCHELATASE ACTIVITY IN MITOGEN-STIMULATED \\ LYMPHOCYTES FROM PATIENTS WITH ERYTHROPOIETIC \\ PROTOPORPHYRIA
}

\author{
S. Sassa, G. L. Zalar, M. B. Poh-Fitzpatrick, K. E. Anderson, and A. Kappas, \\ The Rockefeller University Hospital, New York 10021; Department of \\ Dermatology, Columbia University College of Physicians \& Surgeons, \\ New York 10032
}

A B S T R A C T In this paper we show that the ferrochelatase defect in erythropoietic protoporphyria (EPP) can readily be identified in mitogen-stimulated lymphocytes since such cells from patients with EPP accumulate approximately twice as much protoporphyrin IX as cells from normal subjects when incubated with a porphyrin precursor, $\delta$-aminolevulinic acid (ALA). Treatment of cultures with ALA and with the iron chelator, CaMgEDTA significantly increased the level of protoporphyrin IX in mitogen-stimulated lymphocytes from normal subjects, while the same treatment failed to produce an increase in protoporphyrin IX in cell preparations from EPP patients. In contrast to the results with the chelator treatment, supplementation of the cultures with iron and ALA reduced the level of protoporphyrin IX in normal cells, but not in EPP cells. These findings are compatible with a partial deficiency of ferrochelatase in EPP lymphocytes. The gene defects of acute intermittent porphyria and hereditary coproporphyria have previously been identified using lymphocyte preparations from the gene carriers of these diseases. The present study demonstrates that EPP represents another form of human porphyria in which the gene defect of the disease can now be identified in lymphocyte preparations.

\section{INTRODUCTION}

Erythropoietic protoporphyria (EPP) ${ }^{1}$ is an inherited disorder of porphyrin metabolism characterized clin-

Received for publication 5 October 1981 and in revised form 23 November 1981.

${ }^{1}$ Abbreviations used in this paper: AIP, acute intermittent porphyria; ALA, $\delta$-aminolevulinic acid; EPP, erythropoietic protoporphyria; PBG, porphobilinogen; PHA, phytohemagglutinin; PWM, pokeweed mitogen. ically by photosensitivity and biochemically by marked increases of protoporphyrin IX in erythroid cells, plasma, and feces. In humans EPP is inherited as an autosomal dominant disease with a variable degree of penetrance. This is in contrast to the only other major form of erythropoietic porphyria in man, congenital erythropoietic porphyria (Günther's disease), which is an autosomal recessive disease. However an autosomal recessive form of EPP has recently been described in cattle (1). Previous studies have demonstrated that the activity of ferrochelatase, the last enzyme in the heme biosynthetic pathway, is deficient in a number of tissues and isolated cell preparations from EPP patients, including bone marrow (2), nucleated peripheral blood cells (3), liver (4), and cultured skin fibroblasts (4). A deficiency of ferrochelatase activity would be consistent with the marked increases in protoporphyrin IX found in EPP, since this porphyrin is a substrate for this enzyme.

We have reported earlier the usefulness of a method employing mitogen-stimulated lymphocyte cultures for detecting gene carriers of acute intermittent porphyria (AIP) in which there is a $50 \%$ deficiency of porphobilinogen (PBG) deaminase activity (5). In this method $\delta$-aminolevulinic acid (ALA) added to lymphocytes is metabolized to protoporphyrin IX, which accumulates and is readily measured in such cells. When incubated with ALA, mitogen-stimulated lymphocytes from AIP subjects accumulated $\sim 50 \%$ less protoporphyrin IX than did cells from normal subjects. This was found to reflect a $50 \%$ deficiency of PBG deaminase in these cells of AIP gene carriers, and this enzyme deficiency reflects the gene defect in this autosomal dominant form of porphyria. Using the same technique, in which cells are incubated with ALA, we 
have found that skin fibroblasts from cattle that are heterozygous or homozygous for the EPP gene defect accumulate protoporphyrin IX in amounts that are inversely proportional to the dose of the normal gene for ferrochelatase in these cells (6). Since mitogenstimulated lymphocytes are readily prepared from peripheral blood, our goal in the present study was to determine if this lymphocyte culture system would be useful in identifying individuals who have inherited the gene defect of human EPP.

\section{METHODS}

ALA hydrochloride and crystalline bovine pancreas insulin were purchased from Sigma Chemical Co. (St. Louis, MO). A modified F-12 medium was prepared in our laboratory as previously described (7). RPMI 1640 medium, fetal bovine serum, phytohemagglutinin (PHA) and pokeweed mitogen (PWM) were obtained from Gibco Laboratories, Grand Island Biological Co., Grand Island, NY. Lymphoprep (5.6\% [wt/vol] Ficoll-9.6\% [wt/vol] sodium metrizoate) solution was purchased from Accurate Chemical and Scientific Corp., Hicksville, NY. Plastic culture flasks and tubes were products of Falcon Labware, Becton, Dickinson \& Co., Div. Oxnard, CA.

Subjects studied. Nine patients with EPP ranging in age from 12-46 yr (six clinically affected males, and three clinically affected females) and eight normal subjects ranging in age from 18 to $56 \mathrm{yr}$ (five males and three females) were studied. The clinically affected EPP subjects all had moderate to marked skin photosensitivity and marked increases of protoporphyrin IX in their erythrocytes and plasma. In addition, three clinically latent females had mild, but significantly elevated, levels of protoporphyrin IX in their erythrocytes and plasma; one was the mother and two others were the sisters of the three affected EPP patients.

Cell cultures. Mononuclear cell concentrates were prepared from defibrinated blood by isopyknic sedimentation using Ficoll-metrizoate solution as described previously (5). Contaminating erythrocytes were eliminated by hemolysis with $\mathrm{NH}_{4} \mathrm{Cl}-\mathrm{KHCO}_{3}(5,7)$. Cells were then suspended in RPMI 1640 medium supplemented with $10 \%$ heat-inactivated fetal bovine serum, penicillin $100 \mu \mathrm{g} / \mathrm{ml}$, streptomycin $100 \mu \mathrm{g} / \mathrm{ml}$, and $1 \%$ (wt/vol) PHA, and $1 \%$ (wt/vol) PWM. The final cell concentration was adjusted to $5 \times 10^{5}$ cells/ $\mathrm{ml}$ with the medium. Cell counting was performed using a Cytograf 6300A (Ortho Instruments, Inc., Raritan, NJ). Approximately $2-2.5 \times 10^{7}$ mononuclear cells were usually obtained from $50 \mathrm{ml}$ of peripheral blood. Differential counts from smears of final cell preparations showed 2 granulocytes and 10 erythrocytes per 1,000 nucleated cells. $1 \mathrm{ml}$ of this cell suspension was then transferred to a $12 \times 100-\mathrm{mm} \mathrm{Fal-}$ con plastic tube and incubated at $37^{\circ} \mathrm{C}$ for $72 \mathrm{~h}$ in an atmosphere of $5 \% \mathrm{CO}_{2}$ and $100 \%$ humidity.

Assays. After incubation with mitogens for $72 \mathrm{~h}$, the cells were centrifuged and then washed with $1 \mathrm{ml}$ of serum-free modified F 12 medium supplemented with bovine crystalline insulin $(1 \mu \mathrm{g} / \mathrm{ml})$. This insulin-containing medium (termed "F-I"), was found previously to be useful in the quantitation of porphyrins in chick embryo hepatocytes (7), in human and bovine skin fibroblasts $(6,8)$, and in mitogen-stimulated human lymphocytes (5). Cells were suspended in F-I medium containing $0.6 \mathrm{mM}$ ALA with or without $5 \mathrm{mM}$ CaMgEDTA or $25 \mu \mathrm{M}$ ferrous ammonium sulfate, and then incubated for $24 \mathrm{~h}$ at $37^{\circ} \mathrm{C}$ in a $5 \% \mathrm{CO}_{2}$ atmosphere.
CaMgEDTA is a potent iron chelator and inhibits ferrochelatase in cultured cells since iron is a substrate for the enzyme. This inhibitor does not, however, interfere with the cellular balance of calcium and magnesium which if it occurred would detach cells from the culture dish and interfere with the viability of cells $(7,8)$.

After incubation with ALA for $24 \mathrm{~h}$, cells were harvested by centrifugation at $600 \mathrm{~g}$ for $5 \mathrm{~min}$. Porphyrin was extracted from cell pellets with $500 \mu \mathrm{l}$ of a mixture of equal volumes of $1 \mathrm{~N}$ perchloric acid and methanol. After centrifugation at $600 \mathrm{~g}$ for $5 \mathrm{~min}$ the supernatant was transferred to a $6 \times 50-\mathrm{mm}$ glass test tube (Kimble, Owens-Illinois, Inc. Toredo, $\mathrm{OH}$ ) for porphyrin fluorescence assay. A fluorescence emission spectrum of the extract was obtained in these tubes using a Hitachi-Perkin Elmer model 4 fluorescence spectrophotometer (Perkin-Elmer Corp., Mountain View, CA) equipped with a semimicro-cell holder (8) and a red sensitive photomultiplier R-928. Coproporphyrin $(0.1 \mu \mathrm{M})$ in $0.14 \mathrm{~N}$ $\mathrm{HCl}$ was used as a standard for calibrating the spectrofluorometer. After the perchloric acid-methanol extraction, the cellular precipitate was dissolved in $400 \mu 10.2 \mathrm{~N} \mathrm{NaOH}$ with heating at $60^{\circ} \mathrm{C}$ for $30 \mathrm{~min}$ and protein concentration was determined by the method of Lowry et al. (9). PBG deaminase activity was assayed in $0.5 \times 10^{6}$ cells be a semimicrofluorometric method as described previously (5).

\section{RESULTS}

In both normal and EPP lymphocytes incubated after treatment with PHA and PWM, porphyrin accumulation from the added ALA increased as a function of incubation time as shown in Fig. 1. However, protoporphyrin IX accumulation in EPP lymphocytes at each time interval studied was approximately twice that of normal lymphocytes (Fig. 1). Maximal protoporphyrin IX accumulation was observed when lym-

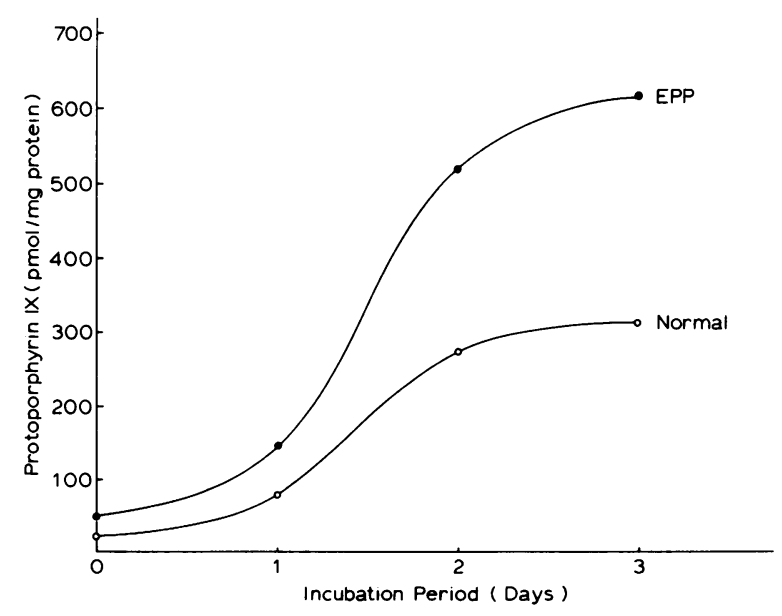

FIGURE 1 Protoporphyrin IX formation as a function of incubation period with the mitogens. Lymphocytes were preincubated with PHA and PWM as described in the text. At the end of incubation (indicated on the abscissa), cells were collected by centrifugation, resuspended in serum-free F-I medium containing $1.2 \mathrm{mM}$ ALA and incubated for 24 h. Points are the mean of triplicate determinations. 
phocytes were incubated with PHA and PWM for 3-4 d before treatment with ALA (Fig. 1). Spectrofluorometric analysis of porphyrins formed by lymphocyte cultures indicated that essentially all porphyrins formed were of the protoporphyrin IX type in both normal and EPP lymphocytes. Porphyrin accumulation was greatest when both $0.5-1 \%$ PHA and $1 \%$ PWM were added, and with cell densities in the range of 0.1 to $1.0 \times 10^{6}$ cells $/ \mathrm{ml}$. In both normal and EPP lymphocytes we found that protoporphyrin IX accumulation after a 3-d preincubation with mitogens was 10-15-fold greater than in cells from the same subjects that were not incubated with the mitogens.

Protoporphyrin IX accumulation was also proportional to ALA concentration (Fig. 2), and was maximal at an ALA concentration of $1.2 \mathrm{mM}$ in both normal and EPP cells. However, this high concentration of ALA was occasionally toxic to the cells, particularly when they had been pretreated with mitogens for $4 \mathrm{~d}$. Cells were therefore routinely incubated with mitogens for $3 \mathrm{~d}$, and subsequently with ALA for 24 h. At all ALA concentrations protoporphyrin IX accumulation was approximately twice as great in EPP lymphocytes as in normal cells (Fig. 2).

Data on protoporphyrin IX accumulation from added ALA in mitogen-stimulated lymphocytes from all the EPP and normal subjects studied are shown in Fig. 3. Protoporphyrin IX accumulation in normal lymphocytes after mitogen stimulation averaged 292 $\mathrm{pmol} / \mathrm{mg}$ protein, whereas in cells from EPP patients the average protoporphyrin IX accumulation was 687 $\mathrm{pmol} / \mathrm{mg}$ protein (Fig. 3A). Protoporphyrin IX accu-

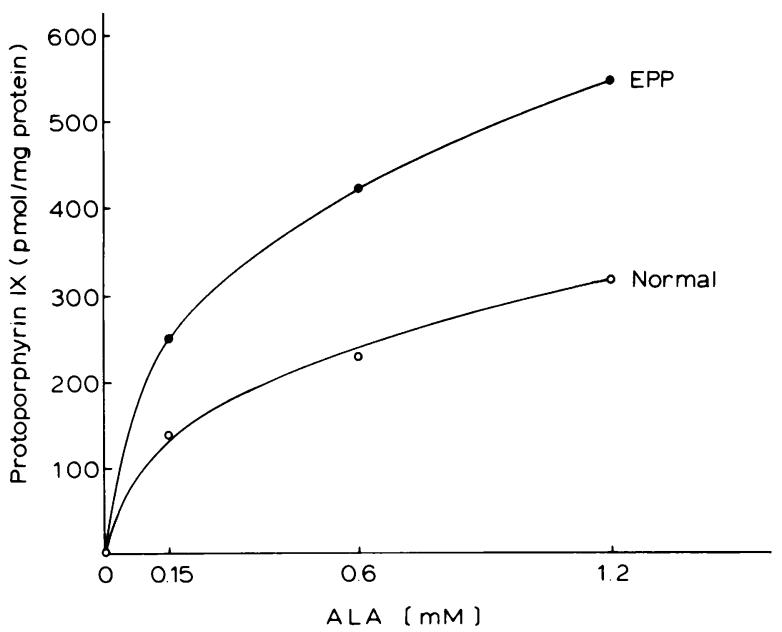

FIGURE 2 Protoporphyrin IX formation as a function of ALA concentration. Lymphocytes were preincubated with PHA and PWM for $3 \mathrm{~d}$ as described in the text. Cells were then incubated for $24 \mathrm{~h}$ with various ALA concentrations. Each data point represents the mean of duplicate determinations.
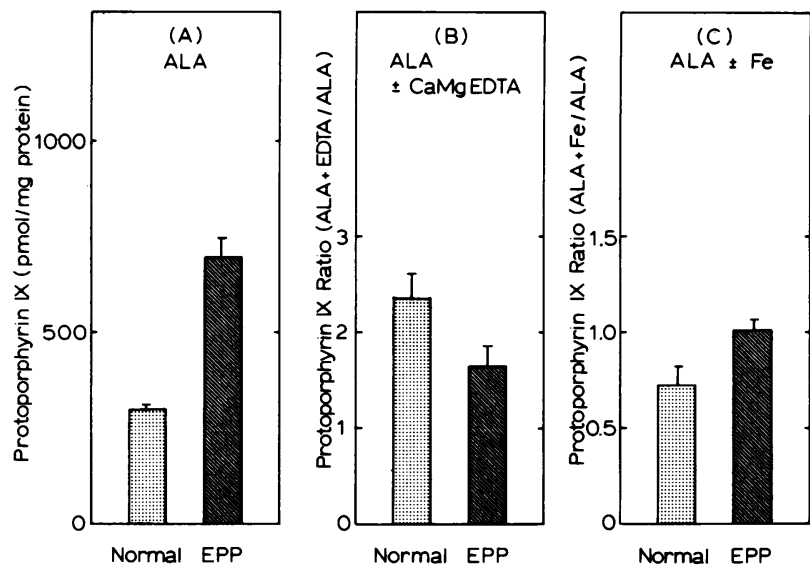

Figure 3 Effects of ALA, CaMgEDTA, and iron on protoporphyrin IX formation. A. Effect of ALA: Data are expressed as the mean $\pm S E$ for eight normal subjects and nine patients with EPP. B. Effect of CaMgEDTA: Data are expressed as the ratio of protoporphyrin IX formed (mean $\pm \mathrm{SE}$ ) with the treatment with CaMgEDTA plus ALA to that formed with ALA alone. C. Effect of iron: Data are expressed as the ratio of protoporphyrin IX formed (mean $\pm \mathrm{SE}$ ) with the treatment with iron plus ALA to that formed with ALA alone.

mulation from ALA in EPP lymphocytes was thus approximately twofold greater than that observed in normal lymphocytes. This finding strongly suggests that ferrochelatase activity in lymphocytes from patients with EPP as determined in the intact cell is functionally deficient and is only $\sim 50 \%$ that of normal cells. Similar findings of excess protoporphyrin IX accumulation from added ALA have been reported in skin fibroblast cultures from patients with EPP (10) and from cattle with an autosomal recessive form of EPP (6).

Our previous studies have shown that the iron chelator CaMgEDTA is an inhibitor of ferrochelatase in cultured chick embryo hepatocytes (7), chick embryo dorsal root ganglion cells $(11,12)$, and bovine skin fibroblasts (6). We therefore examined the effect of CaMgEDTA on protoporphyrin IX accumulation in mitogen-stimulated lymphocytes from EPP patients and normal subjects. Protoporphyrin IX accumulation in normal lymphocytes stimulated with mitogens was increased by treatment with CaMgEDTA, by an average of 2.4 -fold, whereas the average increase produced by CaMgEDTA in EPP lymphocytes was only 1.7-fold (Fig. 3B). Differences in protoporphyrin IX accumulation between normals and EPP patients became less in the presence of CaMgEDTA than in the absence of CaMgEDTA. These findings suggest that less ferrochelatase is present and subject to inhibition by the chelator in EPP lymphocytes than in normal lymphocytes. 
The effect of iron on protoporphyrin IX accumulation in mitogen-stimulated lymphocytes incubated with ALA is shown in Fig. 3C. When normal lymphocytes were incubated with iron and ALA, iron reduced the level of protoporphyrin IX accumulation by $\sim 30 \%$, suggesting that heme formation from protoporphyrin IX is increased when more iron is available (Fig. 3C). A similar effect of added iron has been reported in cultured skin fibroblasts from EPP patients (10). However, when EPP lymphocytes were treated with iron in addition to ALA there was no detectable difference in protoporphyrin IX concentrations (Fig. $3 \mathrm{C})$. These results suggest that the deficient ferrochelatase in the cells from EPP patients is already at its maximum activity and that heme formation cannot be further increased by a greater supply of iron.

We also studied lymphocytes from eight members of a single family (Table I) including three patients with clinically manifest EPP (cases II-2, II-5, II-6) and five clinically unaffected subjects (cases I-1, I-2, II-1, II-3, II-4) three of whom proved to be gene carriers of EPP (cases I-2, II-3, II-4). The three patients with clinically manifest EPP had long-standing cutaneous photosensitivity and markedly elevated protoporphyrin IX in their erythrocytes and plasma (Table I). Accumulation of protoporphyrin IX from added ALA in lymphocytes from these patients was in the range of that for the other EPP patients we studied (Fig. 3). Responses of the cell culture to CaMgEDTA and to iron were, as expected, lower in lymphocytes from the three patients than in cells from normal subjects. Lymphocyte preparations from the father (I-1) and a sister (II-1) accumulated normal amounts of protoporphyrin
IX from exogenous ALA and the responses of their cells to treatment with CaMgEDTA or iron were also normal. Therefore, these two subjects clearly did not carry the EPP gene defect (Table I). The mother (I2) and two sisters (II-3, II-4) were clinically unaffected; however, their plasma contained slightly elevated levels of protoporphyrin IX (Table I). One sister (II-3) was not available for lymphocyte studies, but was also shown to have increased protoporphyrin IX in plasma. The mitogen-treated lymphocytes from the mother (I-2) and another sister (II-4) produced amounts of protoporphyrin IX from ALA that were intermediate between those accumulated in cells from normal subjects and by cells from the members of this family with clinically manifest EPP. Responses of cells from these two subjects (I-2, II-4) to CaMgEDTA or iron treatment were similar to those characterizing the clinically manifest EPP patients. The data from the lymphocyte studies of these two subjects thus clearly identify them as gene carriers of EPP; in view of the absence of an appropriate clinical history of EPP, both subjects can properly be defined as having clinically latent EPP.

\section{DISCUSSION}

The results of the present study demonstrate that a deficiency of ferrochelatase in EPP patients can be detected by incubating mitogen-stimulated lymphocytes with ALA and measuring the amount of protoporphyrin IX that accumulates in the cells. Lymphocytes from EPP patients accumulated approximately twice as much protoporphyrin IX from added ALA

TABLE I

Clinial and Biochemical Findings in a Family with EPP

\begin{tabular}{|c|c|c|c|c|c|c|c|c|}
\hline \multirow[b]{2}{*}{ Subject } & \multirow[b]{2}{*}{ Age } & \multirow[b]{2}{*}{ Sex } & \multirow{2}{*}{$\begin{array}{c}\text { Skin } \\
\text { photo- } \\
\text { sensitivity }\end{array}$} & \multirow{2}{*}{$\begin{array}{c}\begin{array}{c}\text { Erythrocyte } \\
\text { protoporphyrin IX }\end{array} \\
\begin{array}{c}\text { Normal range: } \\
\leq 91\end{array}\end{array}$} & \multirow{2}{*}{$\begin{array}{c}\begin{array}{c}\text { Plasma } \\
\text { protoporphyrin IX }\end{array} \\
\begin{array}{c}\text { Normal range: } \\
\text { s1.0 }\end{array}\end{array}$} & \multicolumn{3}{|c|}{ Protoporphyrin IX formation in mitogen-stimulated lymphocytes } \\
\hline & & & & & & + ALA & ALA + CaMgEDTA/ALA & $\mathrm{ALA}+\mathrm{Fe} / \mathrm{ALA}$ \\
\hline & & & & $\begin{array}{c}\mu g / d l \\
\text { erythrocytes }\end{array}$ & $\mu g / d l$ plasma & $\begin{array}{c}\mathrm{pmol} / \mathrm{mg} \\
\text { protein }\end{array}$ & ratio & ratio \\
\hline I-1 (Father) & 52 & $\mathbf{M}$ & - & 29 & 0.4 & 225 & 2.5 & 0.85 \\
\hline I-2 (Mother) & 46 & $\mathbf{F}$ & - & 65 & 1.9 & 443 & 1.6 & 1.12 \\
\hline II-1 (Sister) & 24 & $\mathbf{F}$ & - & 36.5 & 0.2 & 216 & 2.8 & 0.85 \\
\hline II-2 (Patient) & 22 & $\mathbf{M}$ & +++ & 520 & 24 & 683 & 1.3 & 1.16 \\
\hline II-3 (Sister) & 20 & $\mathbf{F}$ & - & 43 & 1.3 & ND & ND & ND \\
\hline II-4 (Sister) & 18 & $\mathbf{F}$ & - & 45 & 1.9 & 309 & 1.3 & 1.16 \\
\hline II-5 (Patient) & 17 & $\mathbf{M}$ & +++ & 970 & 19 & 724 & 1.7 & ND \\
\hline II-6 (Patient) & 15 & $\mathbf{M}$ & +++ & 1050 & 41 & 808 & 1.2 & 1.07 \\
\hline
\end{tabular}

ND, not determined. 
when compared with cells from normal subjects, indicating that there is a partial deficiency of ferrochelatase activity in EPP cells. We also found that protoporphyrin IX accumulation after ALA treatment was stimulated by CaMgEDTA to a greater extent in lymphocytes from normal subjects than in EPP lymphocytes and that the utilization of protoporphyrin IX for heme formation by added iron in normal lymphocytes was significant, although it was not altered in EPP cells. These findings confirm the existence of a functional deficiency of ferrochelatase in EPP lymphocytes.

The fact that protoporphyrin IX accumulation in EPP lymphocytes after ALA treatment is on average approximately twofold greater than that in normal cells suggests that the functional activity of ferrochelatase in EPP is decreased by $\sim 50 \%$ when this enzyme activity is studied in an intact cell system, as used in this study. Bonkowsky et al. (4) who utilized an in vitro ferrochelatase assay with protoporphyrin IX and radioactive iron as substrates reported that ferrochelatase activity in mitochondrial fractions from EPP fibroblasts was only $\sim 10 \%$ of the activity in normal cells. This is a somewhat unexpected finding in view of the heterozygous status of EPP gene carriers. Since ferrochelatase activity in fibroblasts and most other cultured cells is markedly lower than that in liver and in erythroid precursor cells $(2,4)$, and because there is also a considerable amount of nonenzymatic iron incorporation into protoporphyrin IX in vitro $(13,14)$, it is extremely difficult to assay ferrochelatase activity in isolated mitochondrial fractions from nonhepatic or nonerythroid cells. Using the same radioactive ferrochelatase method used by Bonkowsky et al. (4), we have been unable to quantitate this enzyme activity reproducibly in fibroblast mitochondria or in mitogenstimulated lymphocytes, although we could readily measure the higher levels of ferrochelatase activity in normal rat liver cells. On the other hand, we are able to consistently demonstrate the deficiency of ferrochelatase in cells from EPP patients by the relatively simple and reproducible technique reported here using mitogen-stimulated lymphocytes incubated with ALA. The deficiency of ferrochelatase activity in EPP lymphocytes as determined by our technique averaged $42 \%$ of normal enzymatic activity, and no values in the range of $10 \%$, as reported by Bonkowsky et al. (4), were observed.

It should be noted that Bloomer et al. (10) have reported a twofold greater accumulation of protoporphyrin IX in cultured EPP fibroblasts compared with normal fibroblasts when they were incubated with ALA, a finding that is consistent with our data in lymphocyte cultures. The disparity between the extent of the enzyme deficiency (40-50\%) assessed by protoporphyrin IX accumulation in intact fibroblasts as reported by Bloomer et al. (10) and that $(\sim 90 \%)$ assayed in in vitro mitochondrial preparations from the same cell type reported by the same group $(4,10)$ remains unexplained. It is known that many factors including reductants, endogenous lipids, and trace metals (1517) affect the enzyme activity in vitro and these may bear on the very wide range (13.7-51.5 pmol protoheme $/ \mathrm{mg}$ protein per $\mathrm{h}$ for normal fibroblasts and 60 $580 \mathrm{pmol}$ protoheme $/ \mathrm{mg}$ protein per $\mathrm{h}$ for normal liver biopsy specimens) of ferrochelatase activities reported by Bonkowsky et al. (4). Additionally, the enzyme is known to be quite unstable and to form intractable aggregates during purification (18); variations in its activity could therefore result from in vitro tissue manipulations. In the work we report here, the intact lymphocyte culture system obviated these potential difficulties of the in vitro ferrochelatase assay, and the data obtained indicate an $\sim 50 \%$ deficiency of ferrochelatase activity in EPP, which is consistent with the heterozygous status of these subjects for the gene defect of this disease.

Mailer et al. (18) have demonstrated that the ferrochelatase purified from rat liver mitochondria consists of a single polypeptide with a molecular weight of 63,000 . Ferrochelatase from human sources has not to date been purified to homogeneity. Therefore it is not possible to conclude that the enzyme in EPP cells is structurally different from the normal enzyme, although this has been suggested (19).

A pedigree study of an EPP family (Table I) disclosed that three male subjects were clinically affected EPP patients and that the mother and two of three sisters were latent gene carriers of the disease. In general, clinically expressed EPP affects both sexes equally with possibly a slight male preponderance $(20,21)$ and the exclusive male occurrence of clinically manifest EPP in this family is unusual. An important observation made from this family study is that lymphocytes. from the two clinically latent (i.e. without photosensitivity) gene carriers of EPP (cases I-2, and II-4 in Table I), whom it was possible to study in this fashion, showed intermediate levels of protoporphyrin IX accumulation in lymphocytes after ALA treatment, and their responses to CaMgEDTA or iron were clearly characteristic of clinically expressed EPP subjects. Moreover in the clinically latent subjects in this family, plasma protoporphyrin IX levels were slightly, but significantly, increased and their erythrocyte protoporphyrin IX levels were also greater than the levels of normal family members. Similar increases of protoporphyrin IX in erythrocytes have been reported to occur in latent EPP gene carriers by Reed et al. (20). 
These findings suggest that there can be a difference in the extent of the functional ferrochelatase activity between clinically manifest EPP patients and clinically latent gene carriers of the disease. It is well established that human EPP is an autosomal dominant disorder with a variable degree of penetrance; thus EPP patients as well as latent gene carriers of the disease are presumably heterozygous for a single gene defect. Our findings suggest that although a single gene mutation may explain the genetic defect in EPP, some additional factor(s) is probably required for full clinical expression of the gene lesion in this disorder. An analogous situation exists with respect to the dominant forms of the hepatic porphyrias such as $\operatorname{AIP}(22,23)$. However, the metabolic differences, i.e., those involving endocrine status $(22,23)$ that distinguish completely latent from clinically expressed gene carriers of AIP, do not alter the level of the PBG deaminase deficiency in this disorder $(8,13,24)$. In the case of EPP the nature of the factor(s) that influence the clinical expression of the gene defect of the disease is not known. In an experimental hepatic porphyria induced in mice and rats by treatment with 3,5-diethoxy-carbonyl-1,4-dihydrocollidine, a green porphyrin-like heme breakdown product that potently inhibits ferrochelatase activity is known to be produced in the liver (25). In addition to the primary genetic deficiency of ferrochelatase in EPP, there may also be other factors which affect the activity of the enzyme and identification and characterization of such factors would clearly be important in understanding the mechanism of clinical expression of this disorder.

Finally, only $4 \mathrm{~d}$ are required for the technique described in this method, a time which is much shorter than that required for assays using cultured skin fibroblasts $(6,10,26)$. The lymphocyte culture system is thus considerably more convenient for detecting EPP gene carriers than the fibroblast system. The technique utilizing the incubation of cultured fibroblasts with ALA, ALA plus CaMgEDTA, and ALA plus iron has also been successful in identifying the gene defect in the recessively inherited bovine form of EPP (6) In addition to cattle with clinically manifest EPP who are homozygous for the gene defect of the disease, heterozygous animals who are clinically latent could also be identified by this method.

\section{ACKNOWLEDGMENTS}

We are indebted to Dr. Leonard Harber, Chairman of the Department of Dermatology, Columbia University College of Physicians \& Surgeons, for making available to us the EPP patients described in this study. The technical assistance of Mrs. C. Chang, Mr. S. N. Feltham, and secretarial assistance of Miss Michele Bifano are also gratefully acknowledged.

This work was supported in part by U. S. Public Health
Service grant ES-01055 and AM-18549. Karl E. Anderson is a recipient of Research Career Development Award 1 KO4 GM 00330-04 from the U. S. Public Health Service. It is the 10th study on porphyria by Dr. Sassa et al.

\section{REFERENCES}

1. Ruth, G. R., S. Schwartz, and B. Stephenson. 1977. Bovine protoporphyria: the first nonhuman model of this hereditary photosensitizing disease. Science. (Wash., D. C.) 198: 199-201.

2. Bottomley, S. S., M. Tanaka, and M. A. Everett. 1975. Diminished erythroid ferrochelatase activity in protoporphyria. J. Lab. Clin. Med. 86: 126-131.

3. deGoeij, A. F. P. M., K. Christianse, and I. van Steveninck. 1975. Decreased haem synthetase activity in blood cells of patients with erythropoietic protoporphyria. Eur. J. Clin. Invest. 5: 397-400.

4. Bonkowsky, H. L., J. R. Bloomer, P. S. Ebert, and M. J. Mahoney. 1975. Heme synthetase deficiency in human protoporphyria. Demonstration of the defect in liver and cultured skin fibroblasts. J. Clin. Invest. 56: 1139-1148.

5. Sassa, S., G. L. Zalar, and A. Kappas. 1978. Studies in porphyria VII. Induction of uroporphyrinogen-I synthase and expression of the gene defect of acute intermittent porphyria in mitogen-stimulated human lymphocytes. J. Clin. Invest. 61: 499-508.

6. Sassa, S., S. Schwartz, and G. R. Ruth. 1981. Studies on the formation of protoporphyrin IX from $\delta$-aminolevulinic acid in skin fibroblasts from cattle with erythropoietic protoporphyria. J. Exp. Med. 153: 1094-1101.

7. Sassa, S., and A. Kappas. 1977. Induction of $\delta$-aminolevulinic acid synthase and porphyrins in cultured liver cells maintained in chemically defined medium. Permissive effects of hormones on the induction process. $J$. Biol. Chem. 252: 2428-2436.

8. Sassa, S., G. Solish, R. D. Levere, and A. Kappas. 1975. Studies in porphyria IV. Expression of the gene defect of acute intermittent porphyria in cultured human skin fibroblasts and amniotic cells. Prenatal diagnosis of the porphyric trait. J. Exp. Med. 142: 722-731.

9. Lowry, O. H., A. Rosebrough, A. L. Farr, and R. J. Randall. 1951. Protein measurement with the Folin phenol reagent. J. Biol. Chem. 193: 265-275.

10. Bloomer, J. R., D. A. Brenner, and M. J. Mahoney. 1977 Study of factors causing excess protoporphyrin accumulation in cultured skin fibroblasts from patients with protoporphyria. J. Clin. Invest. 60: 1354-1361.

11. Whetsell, W. O. Jr., S. Sassa, D. R. Bickers, and A. Kappas. 1978. Studies on porphyrin heme biosynthesis in organotypic cultures of chick dorsal root ganglion. I. Observations on neuronal and nonneuronal elements. $J$. Neuropathol. Exp. Neurol. 37: 497-507.

12. Sassa, S., W. O. Whetsell, and A. Kappas. 1979. Studies on porphyrin heme biosynthesis in organotypic cultures of chick dorsal root ganglia. II. The effect of lead. $E n$ viron. Res. 19: 415-426.

13. Tokunaga, R., and S. Sano. 1972. Comparative studies on nonenzymic and enzymic protoheme formation. Biochim. Biophys. Acta. 264: 263-271.

14. Kassner, R. J., and H. Walchak. 1973. Heme formation from $\mathrm{Fe}(\mathrm{II})$ and porphyrin in the absence of ferrochelatase activity. Biochim. Biophys. Acta. 304: 294-303.

15. Porra, R. J., and O. T. G. Jones. 1963. Studies on ferrochelatase: I. Assay and properties of ferrochelatase 
from a pig-liver mitochondrial extract. Biochem. J. 87: 181-185.

16. Labbe, R. F., and N. Hubbard. 1960. Preparation and properties of the iron-protoporphyrin chelating enzyme. Biochim. Biophys. Acta. 41: 185-191.

17. Sawada, H., M. Takeshita, Y. Sugita, and Y. Yoneyama. Effect of lipid on protoheme ferro-lyase. Biochim. Biophys. Acta. 178: 145-155.

18. Mailer, K., and R. Poulson. 1980. Ferrochelatase: Isolation and purification via affinity chromatography. Biochem. Biophys. Res. Commun. 96: 777-784.

19. Bloomer, J. R. 1979. Characterization of deficient heme synthase activity in protoporphyria. Clin. Res. 27: 273A. (Abstr.)

20. Reed, W. B., K. D. Wuepper, J. H. Epstein, A. Redeker, R. J. Simonson, and V. A. McKusick. 1970. Erythropoietic protoporphyria. A clinical and genetic study. JAMA (J. Am. Med. Assoc.). 214: 1060-1066.

21. DeLeo, V. A., M. B. Poh-Fitzpatrick, M. M. MathewsRoth, and L. C. Harber. 1976. Erythropoietic protoporphyria: Ten years' experience. Am. J. Med. 60: 8-22.

22. Kappas, A., S. Sassa, S. Granick, and H. L. Bradlow.
1974. Endocrinegene interaction in the pathogenesis of acute intermittent porphyria. Res. Publ. Assoc. Nerv. Ment. Dis. 53: 225-237.

23. Anderson, K. E., H. L. Bradlow, S. Sassa, and A. Kappas. 1979. Studies in porphyria VIII. Relationship of the $5 \alpha$ reductase metabolism of steroid hormones to clinical expression of the genetic defect in acute intermittent porphyria. Am. J. Med. 66: 644-650.

24. Sassa, S., S. Granick, D. R. Bickers, H. L. Bradlow, and A. Kappas. 1974. A microassay for uroporphyrinogen I synthase, one of three abnormal enzyme activities in acute intermittent porphyria, and its application to the study of the genetics of this disease. Proc. Natl. Acad. Sci. U. S. A. 71: 732-736.

25. Tephly, T. R., A. H. Gibbs, and F. DeMatteis. 1979 Studies on the mechanism of experimental porphyria produced by 3,5-diethoxy-carbonyl-1,4-dihydrocollidine. Role of a porphyrin-like inhibitor of protohaem ferro-lyase. Biochem. J. 180: 241-244.

26. Bloomer, J. R. 1980. Characterization of deficient heme synthase activity in protoporphyria with cultured skin fibroblasts. J. Clin. Invest. 65: 321-328. 